\title{
REFORMA TRABALHISTA E DESPROTEÇÃO SOCIAL: UM DEVIR NEGRO DO MUNDO
}

LABOR REFORM AND SOCIAL DESPROTECTION: THE WORLD BECOMES BLACK

Luciana Garcia de Mello ${ }^{1}$

\section{RESUMO}

O presente artigo procura analisar a relação entre a reforma trabalhista e o processo de generalização da desproteção social. Procurou-se demonstrar que com o desenvolvimento do capitalismo e da industrialização estabeleceu-se um elo entre trabalho e proteção social. No entanto, a partir dos anos 1970, diante da crise estrutural do capital, esse panorama mudou, e o conflito entre capital e trabalho voltou se a tornar cada vez mais desregulamentado. $\mathrm{O}$ horizonte normativo que havia sido construído pela luta da classe trabalhadora se esmaeceu e trabalhadores historicamente inseridos informalmente e de forma precária, como é o caso dos negros, deixaram de vislumbrar em seu horizonte a possibilidade de diminuição das desigualdades que os separam dos brancos. Ao contrário, o que se assiste é uma mudança estrutural, que provoca um devir negro do mundo, indicando assim uma tendência de que a condição da população negra se alastre para boa parte dos trabalhadores.

Palavras-chave: reforma trabalhista; proteção social; devir negro; desigualdade racial.

\begin{abstract}
This article aims to analyze the relationship between labor reform and the process of generalizing social deprotection. We tried to demonstrate that with the development of capitalism and industrialization, a link was established between work and social protection. However, from the 1970s, in the face of the structural crisis in capital, this scenario changes and the conflict between capital and labor becomes increasingly unregulated. The normative horizon that had been built by the struggle of the working class is fading and workers historically inserted informally and precariously, as is the case of blacks, fail to see in their horizon the possibility of reducing the inequalities that separate them from whites. Unlike, what we are witnessing is a structural change, which causes a world black, thus indicating a tendency for the condition of the black population to spread to a large part of the workers.
\end{abstract}

Keywords: labor reform; social protection; world black; racial Inequality.

JEL Classification: J71; K31

\section{INTRODUÇÃO}

À medida que a sociedade salarial foi se desenvolvendo, foram construídas formas de proteção social. Desse modo, nas sociedades modernas há uma íntima relação entre a generalização da condição de assalariado e os mecanismos de proteção social. Como explica Marques (1997), antes da Segunda Guerra havia mecanismos de proteção criados por iniciativa dos trabalhadores ligados à indústria. Tratava-se de um sistema de ajuda mútua, que visava

\footnotetext{
1 Professora do Departamento de Sociologia e do Programa de Pós Graduação em Sociologia da UFRGS.
} 
substituir o vácuo deixado pela destruição das antigas formas de solidariedade associadas às corporações e à vida no campo.

Assim surgiram as coberturas de riscos como doença, desemprego, morte e velhice. A participação do Estado na gestão e na organização da proteção social, que passou a ocorrer no início do século XX, para Marques foi impulsionada pelo crescimento da organização independente dos trabalhadores. OEstado passou a cobrir novos riscos, como aqueles provocados pelos acidentes de trabalho ou pela invalidez. Na primeira fase, os sistemas de proteção estavam voltados aos trabalhadores assalariados urbanos, e a fonte de recursos eram as contribuições de empregados e empregadores. Já a segunda fase dos sistemas de proteção social teve início após o término da Segunda Grande Guerra, momento em que o fordismo se tornou hegemônico nos países centrais. Trata-se do período de construção do Welfare State e, como destaca Marques, apesar das diferenças nacionais, ocorreu a ampliação da cobertura dos riscos e novos segmentos de trabalhadores passaram a ser incorporados à proteção garantida pelo Estado.

O que se deseja sublinhar é que apesar de o capitalismo ser um sistema de exploração universal e provocar uma série de contradições, como salientado por Marx (2017), o conflito entre capital e trabalho aos poucos foi regulamentado, possibilitando que parte dos trabalhadores encontrassem formas de proteção em relação ao mercado.

A partir dos anos 1970 nos países centrais e dos anos 1980 no Brasil, teve início um processo que marcou a passagem da proteção para a desproteção social. A crise estrutural do capital trouxe à tona os discursos e as ações políticas que defendem o neoliberalismo como solução para todos os males e a retirada do Estado do social. Somou-se a isso a superação do fordismo pela acumulação flexível, que provocou impactos bastante negativos sobre o mercado de trabalho. A partir de então, não apenas o desemprego voltou à cena com bastante intensidade, mas sobretudo a qualidade do emprego mudou.

Como sublinha Castells (1999), o trabalho normal tende a desaparecer, e a flexibilização ganha um espaço cada vez maior. Nesse contexto, a proteção social será cada vez mais atacada e em seu lugar passa a haver um clamor tanto pela flexibilização da organização do trabalho quanto pela modificação das regras que regulam essa atividade. A regulamentação até então existente passa a ser vista como um entrave para o desenvolvimento do capital e mesmo como a responsável pelo desemprego. A única solução visada parece ser moldar a mão de obra às necessidades do mercado.

A aprovação da reforma trabalhista em 2017 , por meio da Lei n. ${ }^{\circ} 13.467$, que altera a Consolidação das Leis Trabalhistas que havia sido aprovada em 1. ${ }^{\circ}$ de maio de 1943, e da Lei n. ${ }^{\circ} 13.429$, que ampliou a terceirização e o contrato temporário, é um caso exemplar de medida de desproteção social. Em termos práticos, tem-se a ruptura do horizonte normativo que existia até então. Se antes os trabalhadores informais e precários - majoritariamente negros - podiam almejar formas de proteção social que os equiparasse aos trabalhadores formais, no momento atual há uma inversão que pode ser pensada nos termos de um devir negro do mundo, tal como propõe Mbembe (2014). Tem-se portanto uma mudança estrutural no mercado de trabalho, em que passam a existir de modo predominante atividades informais, mal remuneradas e não protegidas; consequentemente, a realidade até então enfrentada pela população negra tende a se alastrar para o conjunto de trabalhadores.

Este artigo está organizado em três etapas, além desta introdução. Na primeira parte, intitulada "A trajetória da proteção social: caminhos e descaminhos", procurou-se demonstrar, em um primeiro momento, o modo como foi construída a proteção social e a relação desta com o trabalho; em seguida, traz-se à tona a crise do capital e suas repercussões no mundo do 
trabalho, notadamente no que diz respeito à regulamentação do conflito entre capital-trabalho. $\mathrm{Na}$ segunda parte do artigo, denominada "A condição do negro no mercado de trabalho brasileiro", objetivou-se demonstrar a condição vulnerável e precária do trabalhador negro nessa esfera social. Por fim, na terceira parte, denominada "Reforma trabalhista e o devir negro do mundo", buscou-se apresentar o diagnóstico de Mbembe (2014) sobre um devir negro do mundo e relacioná-lo com as transformações que vêm ocorrendo no mercado de trabalho em decorrência da reforma trabalhista. Assim, procurou-se evidenciar que há uma tendência de a condição precária que atinge a maior parte dos indivíduos negros no trabalho se alastrar para boa parte da população economicamente ativa.

\section{A TRAJETÓRIA DA PROTEÇÃO SOCIAL: CAMINHOS E DESCAMINHOS}

Como explica Honneth (2014), até os primeiros anos do século XIX prevaleciam condições de trabalho baseadas em relações tutelares, condicionadas pelo feudalismo agrícola, que obrigavam os membros mais carentes a trabalhar sob um regime de servidão. A Revolução Industrial eliminou da esfera do trabalho todos os elementos tradicionais de servidão ou de trabalho forçado, fazendo surgir a ideia de trabalho livre. No entanto, ainda segundo Honneth, a primeira fase de desenvolvimento do capitalismo industrial foi fortemente afetada pelo pauperismo, fazendo emergir a problemática da questão social. Castel (1998) salienta que o surgimento dessa problemática se deve ao fato de o pauperismo representar uma ameaça à ordem política e social. Assim, Arendt (1997) tem razão ao afirmar que a questão social começou a desempenhar um papel revolucionário quando os homens passaram a duvidar que a pobreza é uma condição inerente à condição humana. Essa tomada de consciência da classe proletária provocou uma reação social e foi um dos fatores que contribuíram para o Estado se tornar responsável pela implementação de políticas sociais.

O paradoxo existente entre trabalho livre e pauperismo possibilitou uma progressiva politização do problema da avaliação das consequências sociais da nova organização do trabalho. As classes trabalhadoras passaram a adotar formas cada vez mais energéticas de resistência e, nessa luta, adquiriram, pouco a pouco, as ideias normativas que haviam sido mobilizadas pelos defensores do capitalismo para legitimar a nova organização do trabalho.

Ainda segundo Honneth (2014), no vocabulário da resistência começaram então a aparecer categorias jurídicas que pareciam tomar literalmente as promessas normativas do mercado; falava-se em "direito ao trabalho", em direitos de proteção do trabalho e formas de assistência elementar e ainda se colocava em questão o problema da exploração. Para o autor, essa luta indica que a ideia de um contrato de trabalho livre já havia sido aceita normativamente pelos trabalhadores, ou pelo menos já tinha se tornado tolerável, e assim teve início uma tentativa de regulamentação da esfera do trabalho que parte dos trabalhadores.

Desde então se abriu uma disputa em torno da questão social, e pode-se dizer que as distintas alas do movimento operário (apesar de suas diferenças internas), quando não tiveram um caráter acentuadamente marxista, lutaram pela radical socialização da liberdade contratual pressuposta pelo mercado capitalista de trabalho (HONNETH, 2014). Progressivamente, foise construindo uma política social estatal e, no final do século XIX, na maior parte dos países liberais da Europa Ocidental, predominava uma nova relação de dependência salarial, na qual o trabalhador não somente era recompensado com um salário, mas também estava inserido em um sistema de proteção social. Nas palavras de Honneth, "El 'pobre' de la primera hora se encaminaba 
ahora, ya fuera por el éxito de sus esfuerzos en la lucha o gracias a la previsión política del Estado, a convertirse en el assalariado con estatus protegido del siglo XIX” (2014, p. 307).

É preciso destacar que no curso do desenvolvimento do capitalismo nos países ocidentais a proteção social assumiu três formas principais: assistência social, seguro social e Estado de Bem-Estar Social. Há variações de acordo com cada país, e essas três formas não se desenvolveram de modo linear, havendo sobreposição entre elas.

Em relação às formas de proteção social, Castel explica que a assistência social ou o social-assistencial se formou no Ocidente Cristão a partir dos séculos XII e XIII e tinha os principais traços de uma política assistencial moderna: diversas instituições sociais, tais como o hospital e o orfanato, e a distribuição de esmolas começaram a ser organizados para atender a população carente. Esse social-assistencial apresentava-se como um conjunto de práticas com funções, em um primeiro momento, protetora e integradora (visto que elas permitem uma sociabilidade secundária) e mais tarde preventiva, ou seja, tratava-se de uma intervenção da sociedade sobre "si mesma" (CASTEL, 1998). Nesse momento, houve o reconhecimento de uma necessidade, mas prevaleceu a ideia de que a situação de necessidade decorre de um problema de caráter do necessitado (TEIXEIRA, 1985; CASTEL, 1998). A solução adotada foi trabalho forçado para os capazes, assistência para os incapazes e repressão para os vagabundos. No social-assistencial tem-se uma condição de cidadania invertida, pois o indivíduo passa a se relacionar com o Estado no momento em que se reconhece como não cidadão, ou seja, ele tem como atributos jurídicos e institucionais, respectivamente, a ausência de uma relação formalizada de direito ao benefício (as políticas assistenciais são instáveis), e a base institucional reproduz um modelo de voluntariado das organizações de caridade, mesmo quando exercidas em instituições estatais (TEIXEIRA, 1985).

Conforme Castel, no final do século XVII e início do século XVIII, ficou clara a percepção de que as políticas tradicionais de distribuição de auxílios e de trabalho forçado são insuficientes para resolver a questão social, uma vez que elas só agem sobre as áreas de assistência ou de desfiliação. Outra constatação é que o trabalho, que havia sido convertido em fonte de riqueza, não cumpre esse papel. Pelo contrário, é justamente o modo de organização do trabalho que gera a miséria e a vulnerabilidade de massa. Isso significa que a população inserida no mercado de trabalho também carecia de assistência. Havia diferenças entre os países ocidentais, mas no início da industrialização a ideia de proteção social foi rejeitada. Inicialmente, o liberalismo não comportava uma feição democrática, pelo contrário, o pressuposto da liberdade individual, e mesmo o da igualdade, opunham-se às medidas de proteção social. E mais, na primeira metade do século XIX ficou evidente para as nações desenvolvidas a discrepância entre o progresso social e o econômico. Desse modo, o Estado não foi acionado para solucionar os problemas sociais. Foram criadas novas redes de interdependência entre superiores e inferiores. Castel destaca que ainda é mantida uma relação de continuidade com o social-assistencial. Há uma tentativa de criar um compromisso ético de ajuda. O princípio das associações de auxílio mútuo se expande e ganha força também junto às empresas, emergindo assim a tutela patronal.

O sistema de proteção patronal também tinha limitações: a primeira era de ordem técnica (isso porque a organização do trabalho em larga escala impõe relações cada vez mais objetivas, formais), e a segunda era a impossibilidade de considerar, nesse contexto, as reivindicações próprias dos operários e suas formas específicas de organização (CASTEL, 1998). Em síntese, o sistema de proteção patronal chocava-se com os interesses dos trabalhadores. O antagonismo entre essas duas classes sociais foi tal que se fez necessária a figura de um mediador: o Estado. Isso provocou uma mudança expressiva. No final do século XIX, com a organização do movimento operário e a ampliação de direitos políticos, aumentou a pressão da classe operária, 
e o liberalismo se transformou em uma doutrina liberal-democrática. Assim, surgiu uma nova tecnologia de proteção: o seguro social. A principal diferença entre esse sistema e o social-assistencial é que o primeiro não representa uma relação de tutela, mas de obrigação mútua. De acordo com Fleury (1994), no primeiro momento o seguro era restrito à classe assalariada, mas esse princípio de elegilidade foi relaxado e se ampliou a cobertura do sistema, dando origem ao Welfare State que se desenvolveu mais tarde no século XX.

Nesse contexto, surge uma noção que se torna fundamental: uma sociedade democrática poderia ser legitimamente desigual, desde que nela não houvesse uma relação de tutela, e sim de solidariedade, e admitia-se que ela não poderia realizar a igualdade de condições, pois havia uma diferenciação "orgânica" (CASTEL, 1998). Disso decorre a afirmação do autor de que o Estado pode e deve intervir com o objetivo de fazer justiça a cada um em seu lugar. As práticas de recursos fornecem uma matriz operacional que pode ser aplicada a inúmeras situações: pode-se estar coberto contra acidentes, incêndios, doenças, desemprego etc. A vida social é assimilada a certo número de riscos sociais. Diante de tal leque de possibilidades, o Estado trata de assegurar os indivíduos contra os riscos particularmente importantes e significativos porque estes têm implicações sobre o interesse coletivo e ameaçam a coesão social.

Ainda segundo Castel, há outra implicação da promoção do seguro: uma transformação da propriedade, a fundação de um tipo de propriedade social que, embora tenha uma gênese histórica, até o momento não havia se apresentado como tal. A reformulação da questão social não acaba com a oposição entre proprietário e não proprietário, mas trata de redefini-la, justapondo à propriedade privada outro tipo, que é a propriedade social. Dessa forma, o indivíduo pode ficar sem a primeira, mas dentro de um sistema de seguridade.

Seguridade e trabalho vão tornar-se substancialmente ligados porque, numa sociedade que se reorganiza em torno da condição de assalariado, é o estatuto conferido ao trabalho que produz o homólogo moderno das proteções tradicionalmente asseguradas pela propriedade (CASTEL, 1998, p. 387).

Castel afirma que o Estado não distribui benefícios, apenas foi "eleito" o guardião de uma nova ordem de distribuição dos bens. Os recursos propriamente ditos vêm do próprio indivíduo, ou mais especificamente dos assalariados. A vantagem para esses últimos é que há uma nova significação para o salário, pois esse já não é apenas a retribuição do trabalho, mas comporta uma parte que constitui uma renda do trabalho para situações fora de trabalho. Inicialmente essas situações são negativas, tais como doença, acidente, velhice improdutiva, entre outras. Posteriormente, elas também são definidas de modo positivo, como a possibilidade de consumir, de se instruir, de ter lazeres (1998).

Na visão de Teixeira (1985), no sistema de seguros há uma cidadania regulada, pois depende, em grande medida, do exercício de uma ocupação oficialmente reconhecida. As instituições responsáveis pela prestação de serviço e pelos benefícios tendem a ser financiadas com base na contribuição salarial e por demais aportes do Estado. Se por um lado essa forma de proteção envolve questões de justiça, equidade e redistribuição de renda entre a população assistida, por outro ela exclui os que estão à margem do mercado de trabalho formal. Isso significa que a relação entre trabalho e proteção social está restrita aos trabalhadores inseridos no mercado formal.

No século XX, após a Segunda Guerra, as políticas sociais ganharam um impulso ainda maior com o desenvolvimento do Estado de Bem-Estar. Como se procurou demonstrar, o Welfare State é uma construção histórica, havendo várias teorias explicativas sobre seu surgimento e desenvolvimento. Embora não haja consenso, como explica Arretche (1995), para 
autores como Harold Wilensky, Richard Titmuss e Thomas H. Marshall seu surgimento está relacionado às mudanças ocorridas na sociedade devido à industrialização.

Ainda segundo a autora, para Clauss Offe e James O'Connor esse estado é uma resposta às necessidades de acumulação e legitimação capitalista. Em alguma medida, o Estado passa a organizar a exploração capitalista, ampliando seu aparato e assumindo um papel central no processo de acumulação capitalista. $\mathrm{O}$ aumento da produtividade do capital ocorre paralelamente ao aumento de renda do trabalhador. Assim, pode-se afirmar que o Welfare State pode ser visto como uma nova forma de regular o conflito capital-trabalho e garantir proteção social.

Esping-Andersen (1991), tomando como critério a democratização social do capitalismo, criou uma tipologia de regimes de bem-estar. Assim, são identificados três modelos: $\left.1 .^{\circ}\right)$ modelo conservador, em que os direitos e deveres são vinculados ao status ocupacional e não à cidadania; $2^{\circ}$ ) modelo liberal, que maximiza o status mercantil do trabalho assalariado, desqualificando e punindo os usuários dos serviços sociais; $3 .^{\circ}$ ) modelo da democratização social, que envolve a desmercantilização dos salários e do consumo, e no qual a sociedade é reestratificada em princípios solidários; há correções redistributivas e pleno emprego. Esse último corresponde ao regime de Estado de Bem-Estar no sentido pleno do termo.

Fleury (1994) sublinha que a principal mudança que ocorrerá nas políticas sociais empreendidas nesse Estado é o rompimento com as noções de proteção social com base na evidência da necessidade ou no contrato firmado, estabelecendo-se assim uma relação de cidadania plena.

Evidentemente que o Brasil não seguiu a mesma trajetória dos países ocidentais, mas Draibe (1989) propõe que, se entendermos Welfare State como uma forma particular de regulação social que se expressa pela transformação das relações entre Estado e economia e entre o Estado e a sociedade, em dado momento do desenvolvimento econômico, entre os anos 1930 e a década de 1970, construiu-se e consolidou-se institucionalmente no Brasil um Estado Social.

Para Carvalho (2008), ainda que tenham se apresentado vários entraves e falhas no sistema de proteção social que foi se consolidando ao longo dos anos em nosso país, é inegável que o período de 1930-1945 pode ser caracterizado como a era dos direitos sociais, notadamente para os trabalhadores assalariados. Nesse contexto, o elo entre trabalho e proteção social foi se fortalecendo, e deve-se salientar que para além da implantação de uma legislação trabalhista, houve também a adoção de uma legislação previdenciária e a organização dos sindicatos. Ocorreu ainda um processo de institucionalização da proteção social. Assim, em 1930 foi criado o Ministério do Trabalho, Indústria e Comércio, e em 1931, o Departamento Nacional do Trabalho.

Ainda segundo Carvalho, no ano seguinte foi decretada a jornada de 8 horas no comércio e na indústria; regulamentou-se o trabalho feminino, sendo proibido o trabalho noturno para as mulheres; estabeleceu-se salário igual para homens e mulheres; regulou-se o trabalho dos menores de idade; criou-se a carteira de trabalho.

Em 1933, houve avanços em relação à previdência social dos trabalhadores formais, quando foram criados os Institutos de Aposentadoria e Pensão. Particularmente importante foi a promulgação do Decreto n. ${ }^{\circ}$ 5.452, de 1 . $^{\circ}$ de maio de 1943 , que aprovou a Consolidação das Leis do Trabalho (CLT). Esse documento é um marco importante, pois por meio dele se passou a regular as relações entre capital e trabalho. No entanto, categorias importantes de trabalhadores, como os autônomos, os trabalhadores domésticos e os trabalhadores rurais ficaram excluídos da proteção social em um primeiro momento. Somente em 1972 foi estendida a cobertura da 
previdência aos trabalhadores autônomos e domésticos. Quanto aos trabalhadores rurais, apesar de ter sido aprovado um estatuto para eles em 1963, apenas com a Constituição Federal de 1988 houve a universalização dos benefícios previdenciários para essa categoria. De qualquer modo, é inegável que as relações de trabalho se tornaram mais regulamentadas e o trabalho formal ficou mais protegido.

Entre o período pós-guerra e meados dos anos 1970, o capitalismo viveu sua "Era de Ouro". A maior parte das nações ocidentais adotou o compromisso keynesiano-fordista e viu o fortalecimento de seus estados de previdência. $\mathrm{O}$ fordismo era um novo modo de regulação do sistema capitalista que visava, além do aumento da produtividade e do lucro, o aumento do consumo. Em outras palavras, produzir em massa, para um mercado consumidor massificado. A isso se aliava o keynesianismo com o pleno emprego, que aliviava a pobreza. Cumpre salientar que as mudanças no processo produtivo favoreceram a ampliação e o fortalecimento social e político das classes médias.

\begin{abstract}
Naturalmente a maior parte da humanidade continuava pobre, mas nos velhos centros industrializados, que significado poderia ter o "De pé, ó vítimas da fome" da "Internationale" para trabalhadores que agora esperavam possuir seu carro e passar férias anuais remuneradas nas praias da Espanha? E se os tempos se tornassem difíceis para eles, não haveria um Estado previdenciário universal e generoso pronto a oferecerlhes proteção, antes nem sonhada, contra os azares da doença, da desgraça e mesmo da terrível velhice dos pobres? Suas rendas cresciam ano a ano, quase automaticamente. Não continuariam crescendo para sempre? A gama de bens e serviços oferecidos pelo sistema produtivo, e ao alcance deles, tornava antigos luxos itens de consumo diário. E isso aumentava a cada ano. Que mais, em termos materiais, podia a humanidade querer, a não ser estender os benefícios já desfrutados pelos povos favorecidos de alguns países aos infelizes habitantes de outras partes do mundo, reconhecidamente ainda a maioria da humanidade, que não haviam entrado no "desenvolvimento" e na "modernização"? (HOBSBAWM, 2000, p. 262-263).
\end{abstract}

Mesmo no Brasil, a situação melhorou nesse período para os trabalhadores. Segundo Pochmann (1999), diminuiu a participação relativa das ocupações sem registro, sem remuneração e por conta-própria e também o desemprego, possibilitando a incorporação crescente de parcelas da população economicamente ativa (PEA) no mercado de trabalho. Ao comparar os censos demográficos de 1940 e 1980, Pochmann ainda concluiu que, nesse período, de cada dez ocupações geradas, oito eram assalariadas, sendo sete com registro em carteira. Além disso, ocorreu um movimento de consolidação dos segmentos ocupacionais organizados no meio urbano, e o setor secundário da economia (principalmente a indústria de transformação) revelou um aumento da participação relativa das ocupações. Por outro lado, os que estavam fora do mercado de trabalho formal continuavam sujeitos a uma proteção de base filantrópica e assistencialista, inexistindo a eles uma concepção de direitos.

Nos países ocidentais, o panorama começa a mudar nos anos 1970. De acordo com Harvey (1999), entre 1965 e 1973 ficou claro que o fordismo e o keynesianismo ${ }^{2}$ não podiam conter as contradições inerentes ao capitalismo. Tanto a rigidez do planejamento econômico quanto a dos compromissos do Estado se tornaram problemáticas. Apesar de ter sido estabelecido um elo entre capital, trabalho e governo, havia uma hierarquia entre eles, sendo que o grande capital era o fator principal.

\footnotetext{
2 Apesar dos adeptos da teoria do economista John Keynes defenderem o livre mercado capitalista, também era apregoada a necessidade de uma forte intervenção econômica do Estado, visando, entre outras coisas, garantir o pleno emprego.
} 
Ainda segundo Harvey, as décadas de 1970 e 1980 foram um período de reestruturação econômica e de reajustamento social e político. O fordismo foi substituído pela acumulação flexível, que se apoia na maleabilidade dos processos de trabalho, dos mercados de trabalho, dos produtos e padrões de consumo. Flexibilidade, desemprego e precarização estão diretamente associados a essa fase de acumulação flexível do capital. E, como sublinha Castells (1999), o emprego normal - jornada de 35-40 horas, compromisso com permanência futura, contrato entre patrão e empregado com direitos bem definidos, níveis padronizados de salário, plano de carreira etc. - começou a declinar no mundo inteiro, favorecendo essa flexibilidade. Em vez de estabilidade, doravante tem-se observado trabalhos regidos por tarefas, trabalhos fora da empresa e subcontratação. Assim, portanto, a tendência geral é tornar o mercado de trabalho cada vez mais flexível, e isso deve ser entendido em todos os sentidos, ou seja, a flexibilidade atinge a produção, os contratos, os salários e tudo o mais que está relacionado a essa esfera social.

Paralelamente às mudanças no mundo do trabalho, aconteceram transformações nos Estados Nacionais, dado que estes perderam seus poderes econômicos nas décadas de crise. $\mathrm{Na}$ batalha entre keynesianos e liberais, esses últimos tomaram a frente após 1974. Como explica Hobsbawm (2000), os primeiros afirmavam que salários altos, pleno emprego e o Estado de Bem-Estar criaram uma demanda de consumo que alimentou a expansão, e bombear mais demanda na economia era a maneira mais eficaz de lidar com depressões econômicas. Por outro lado, os neoliberais alegavam que a economia e a política da Era de Ouro impediam o controle da inflação e o corte de custos tanto no governo quanto nas empresas privadas.

Seja como for, desde a década de 1970 tem havido um retrocesso nas políticas sociais do Estado: cortes em programas sociais; esquemas de coparticipação nos custos dos serviços; privatizações de determinadas áreas da saúde, da habitação, da educação. Além disso, ainda conforme Santos (1996), há o aumento de transferência da prestação de serviços para o setor privado, e as redes de interconhecimento e de entre-ajuda voltaram a ser mobilizadas. $\mathrm{O}$ autor sublinha ainda que as ideias de mercado e as que gravitam em sua órbita (autonomia, liberdade, iniciativa privada, concorrência, mérito, lucro) têm desempenhado um papel decisivo na desarticulação da rigidez da relação salarial herdada do período anterior e no desmantelamento relativo do Estado-providência.

É nesse contexto que o programa neoliberal, adotado inicialmente na Inglaterra e nos Estados Unidos, passou a defender o recuo das fronteiras do Estado de Bem-Estar, como sinalizam Dardot e Laval (2016). A partir de então, passaram a ser defendidas reformas neoliberais como remédio universal para todos os males da sociedade. Direitos e garantias duramente conquistados começaram a ser retirados. Deve-se sublinhar que no Brasil esse quadro é ainda mais grave, já que nosso país construiu um sistema de proteção social bastante modesto se comparado ao dos países centrais.

O que se assiste nesse momento é um processo de inversão histórica. Para Honneth (2014), o problema crucial é que o potencial normativo do mercado de trabalho, e mesmo de algumas esferas sociais contingentes a ele, começa a desaparecer. Ainda segundo o autor, em consequência do desbloqueio dos interesses empresariais de lucro, do entrelaçamento internacional de empresas e das estratégias de produção transnacional, o estatuto normativo dos assalariados começa a ruir de tal forma que existe uma perda real dos logros obtidos até o momento. Nesse contexto, em vez de se ampliarem as formas de regulação do conflito capital-trabalho e esse último se tornar cada vez mais protegido, aumentam a exploração e a vulnerabilidade dos trabalhadores, fazendo com que sua luta nos dias atuais seja equiparada àquela desenvolvida nos primórdios do desenvolvimento do capitalismo. Nesse contexto, a 
situação de trabalhadores que ficaram à margem da proteção social, como é o caso da maior parte dos indivíduos negros, tende a se alastrar para o conjunto da população economicamente ativa. $\mathrm{Na}$ etapa seguinte, apresentaremos a condição do trabalhador negro no mercado de trabalho brasileiro, evidenciando sua precarização e vulnerabilidade.

\section{A CONDIÇÃO DO NEGRO NO MERCADO DE TRABALHO BRASILEIRO}

A inserção precária da população negra ${ }^{3}$ no mercado de trabalho tem raízes históricas. Como explica Quijano (2005), a constituição da América e do capitalismo colonial/moderno fez emergir um novo padrão de poder mundial, que tem como um dos eixos fundamentais a classificação social da população mundial com base na ideia de raça. As relações sociais que se configuraram nesse contexto eram de dominação e produziram identidades que foram associadas a hierarquias, lugares e papéis sociais correspondentes ao padrão de dominação que se impunha.

Essas novas identidades produzidas com base na ideia de raça foram, por sua vez, associadas a atribuições e lugares na nova estrutura global de controle do trabalho. Desse modo, como argumenta Quijano (2005), raça e divisão do trabalho foram estruturalmente associados e passaram a reforçar-se mutuamente, ainda que nenhum dos dois fosse necessariamente dependente do outro para existir ou se transformar. Essa distribuição racista do trabalho que se formou no interior do capitalismo colonial/moderno se manteve durante todo o período colonial. Aqueles que passaram a ser chamados de europeus devido a essa lógica de classificação racial associaram o trabalho não pago ou não assalariado com as raças dominadas, pois estas eram vistas como inferiores. Para os europeus ou brancos, o trabalho pago era um privilégio pertencente somente a eles, e a inferioridade racial dos colonizados implicava que esses últimos não eram dignos de salário.

Essa mentalidade perdurou no pós-abolição da escravatura. No Brasil, quando o trabalho livre e assalariado começou a ser implementado, os negros foram considerados inadequados para o mercado de trabalho que estava se formando. Dois motivos principais explicam essa postura diante da população negra: $1 .^{\circ}$ ) esse grupo era considerado inapto porque havia sido socializado no regime da escravidão, trabalhando apenas se fosse forçado e sendo, portanto, uma mão de obra não adaptável ao trabalho livre do sistema capitalista de produção; $2 .^{\circ}$ ) esperava-se que com o novo regime de trabalho a nação alcançasse maior desenvolvimento e progredisse.

Como explica Ortiz (1985), a ideia de progresso no pensamento de boa parte da elite brasileira significava, sobretudo, um país mais branco. Assim, após a alteração no regime de trabalho, a mão de obra preferencial passou a ser os imigrantes europeus. Segundo Skidmore (1989), em 1886 os fazendeiros paulistas fundaram a Sociedade Promotora da Imigração, destinada a recrutar imigrantes europeus, preferencialmente da Itália, para trabalhar nas plantações de café. Em 1889 esse programa de imigração subvencionada foi encampado pelo governo do Estado de São Paulo, que utilizava recursos públicos para arcar com as despesas de transferência dos imigrantes, informa o autor. Tal política perdurou até 1928, quando já havia mão de obra suficiente. Onde houvesse imigrantes, fatalmente não haveria o pretendente "negro" ou "mulato", pois se entendia que ele era o 'agente natural' do trabalho (FERNANDES, 1978).

\footnotetext{
3 Será utilizado o termo "negro" ou "negra" para se referir à população preta e parda.
} 
Desse modo, como destaca Pochmann (2008), o processo de transição do trabalho escravo para o trabalho livre criou um exército de desocupados, e grande parte da população de ex-escravos e de seus descendentes se tornou excedente para as necessidades do capital agrário. O negro que foi para as cidades viveu predominantemente na desocupação, na informalidade e em ocupações precárias.

A alternativa que os brancos criaram para os negros, após a abolição da escravatura, foi continuar trabalhando nas mesmas condições que antes ou "reagir a tudo o que o trabalho desqualificado pela escravidão significava, passando a viver na sociedade e no desregramento" (CARDOSO, 2003, p. 315). Nas cidades, a maioria da população negra não aceitou continuar trabalhando nas atividades que estavam fortemente relacionadas com o trabalho servil, e tal recusa serviu para reforçar a imagem negativa que se tinha da população negra. Visualizava-se um estereótipo dos libertos que os apresentava ora como incapazes e despreparados, precisando por isso de tutela e amparo, ora como viciosos e de alta periculosidade, necessitando de permanente vigilância e controle. Contribuía, evidentemente, para a consolidação desta última imagem o acirramento da resistência escrava nos anos que precederam à extinção final do regime servil (PESAVENTO, 1989).

Outro motivo para a discriminação dos negros, informa a autora, foi o fato de alguns deles estarem engajados no trabalho ocasional e irregular, exercendo assim as funções de vendedores ambulantes, quitandeiros, biscateiros, entre outras. A elite fazia o possível para coibir essas formas de trabalho, uma vez que desejava ter controle sobre a população negra, e essa tarefa se tornava mais difícil na medida em que os negros não estivessem formalmente empregados, informa Pesavento (1989).

Além disso, muitos negros que eram atraídos para os centros urbanos em busca de trabalho não conseguiam se inserir em tipo algum de atividade e se tornavam vadios ou infratores, envolvendo-se inclusive na prostituição. Esses negros serviam ainda para aumentar o contingente da população pobre que vivia nas cidades. Assim, o preconceito não apenas se intensificou, mas também mudou de conteúdo. Segundo Cardoso (2003), na sociedade de castas a base para discriminar os negros era sua posição social (escravos), já na sociedade de classes é a própria cor da pele ou outros atributos raciais distinguíveis, reais ou imaginários, que servem de fonte para a seleção de qualidades estereotipáveis. Foram criadas barreiras de "raça", conforme o autor, para que os negros fossem acomodados em um sistema de atribuição de posições e vantagens bastante assimétrico.

Assim, o negro passou a conviver com dois problemas no mercado de trabalho: a desigualdade racial e a inserção em condições precárias. $\mathrm{O}$ mercado de trabalho não segue uma trajetória linear, mas em relação às desigualdades entre brancos e negros houve, ainda que de modo muito lento, uma diminuição ao longo do tempo. Em 1931, o governo brasileiro criou a Lei dos Dois Terços, que obrigava as empresas a contratarem esse percentual mínimo de trabalhadores nacionais. A essa altura os imigrantes já formavam o núcleo central da classe trabalhadora em São Paulo, conforme Silva e Hasenbalg (1992), mas de qualquer modo o negro começava a se inserir no mercado de trabalho formal, sobretudo, nas atividades que eram rejeitadas pelo trabalhador branco.

Nas décadas seguintes, a conjuntura favorável do mercado de trabalho possibilitou que a participação do trabalhador negro se ampliasse. Segundo Silva e Hasenbalg (1992), o Censo Demográfico de 1950 demonstra que o número de negros no setor industrial aumentou mais rápido que o de brancos, mas mesmo assim havia um percentual de ocupados brancos que superava em $4 \%$ o de negros. 
Novas análises sobre a forma de participação dos negros no mercado de trabalho só foram possíveis no final da década de 1970, quando foi criada a Pesquisa Nacional por Amostragem de Domicílio (PNAD). A pesquisa de 1976 demonstrou a existência de uma desigualdade socioeconômica bastante expressiva entre brancos e não brancos, fazendo com que Silva e Hasenbalg (1992) afirmassem que "A cor das pessoas é um determinante importante das chances de vida e a discriminação racial parece estar presente em todas as fases do ciclo de vida individual" (1992, p. 113). Esses autores destacam que o crescimento econômico propiciou certo grau de mobilidade da população negra, mas não evitou que ela permanecesse concentrada nos estratos socioeconômicos inferiores do mercado de trabalho. Em parte, isso pode ser explicado pelos diferenciais de qualificação dos dois grupos e pelo fato de a educação e a experiência terem retornos desiguais para brancos e não brancos. Nesse segundo caso, haveria indícios da existência de discriminação racial.

Lovell (1995) também procurou verificar a influência do desenvolvimento brasileiro, ocorrido entre os anos 1960 e 1980, sobre as desigualdades raciais e de gênero no emprego e nos salários: quanto ao mercado de trabalho, o desenvolvimento permitiu que as oportunidades fossem ampliadas e removeu algumas barreiras tradicionais ao emprego, informa a autora, mas também persistiram diferenças que são explicadas somente pelo efeito da raça e do gênero. Essas desigualdades são especialmente significativas, e perdura uma desvantagem relativa de pretos e pardos, principalmente nas ocupações mais valorizadas socialmente. Essas conclusões foram corroboradas por Telles (2003), que também constatou a existência de uma relação entre o aumento do dinamismo no mercado de trabalho e a diminuição dos níveis gerais de desigualdade racial nessa área, sobretudo na base da estrutura ocupacional. Da mesma forma, o autor percebeu que no topo da estrutura social a desigualdade se mantém em índices bastante elevados. O autor destaca que, aproximadamente, metade da diferença da desigualdade racial encontrada nas regiões metropolitanas brasileiras pode ser atribuída às diferenças na desigualdade educacional.

Em grande medida, as desigualdades raciais diminuíram entre os anos 1960 e 1980, pois, como explica Arretche (2015), a economia brasileira cresceu de modo espetacular e o PIB triplicou. Além disso, houve uma acelerada desruralização e absorção precária de trabalhadores com baixa qualificação. Nos anos 1980 esse panorama começou a mudar. A intensificação do processo de globalização e a mundialização da economia causaram impacto desfavorável nas indústrias brasileiras nesse período, sobretudo nos anos 1990.

Cumpre salientar que no início dos anos 1990, o governo brasileiro se inseriu no processo produtivo globalizado, abrindo seu mercado, criando a necessidade de as empresas se reestruturarem para aumentar a produtividade e agregar valor a seus produtos, por meio da inovação e da tecnologia. Essa transição para a nova economia afetou não apenas as empresas, mas também os trabalhadores. De acordo com Pochmann (1999), a capacidade de gerar empregos diminuiu e paralelamente tornaram-se mais precárias as formas de inserção da população já ocupada. Para além disso, como destaca Comin (2015), o ciclo da industrialização já perdera o fôlego, fazendo com que as melhores oportunidades de mobilidade social ascendente se deslocassem para o setor de serviços, no qual os requisitos educacionais tendem a ser mais elevados. Isso teve um impacto negativo para a população negra, entre outros motivos, devido a sua baixa escolaridade, informa o autor.

Henriques (2001) analisou, entre 1992 e 1999, o grau de informalidade - definido como a proporção de ocupados na posição por conta própria, empregados sem carteira, trabalhadores sem remuneração ou produzindo para o autoconsumo - e de assalariamento - entendido como a proporção de ocupados que são funcionários públicos e empregados com carteira. $\mathrm{O}$ 
resultado da pesquisa demonstra que durante toda a série histórica o grau de informalidade dos trabalhadores negros é maior do que aquele dos trabalhadores brancos; inversamente, o grau de assalariamento dos brancos é sempre superior.

Em 1999, por exemplo, o grau de informalidade dos negros era de praticamente $60 \%$; já para os brancos esse percentual ficava em $48 \%$. O autor afirma ainda que o nível de precariedade dos postos de trabalho é sempre maior para os negros do que para os brancos. Esse dado também é destacado por Paixão (2003), conforme o qual a proporção de negros em ocupações precárias, em cinco das seis regiões metropolitanas cobertas pela PED, era superior à casa dos 40\% ${ }^{4}$. Além disso, Henriques (2001) traz uma evidência bastante contundente: o diferencial entre esses dois grupos no que se refere aos graus de industrialização e modernidade dos postos de trabalho aumenta ao longo do tempo, em detrimento dos trabalhadores negros.

No início dos anos 2000, o panorama voltou a ser positivo, sobretudo após a eleição do então presidente Luiz Inácio Lula da Silva. Como destacam Proni e Gomes (2015), a partir de 2004, momento em que se configurou um quadro macroeconômico favorável e uma trajetória de reestruturação do mercado de trabalho nacional, a redução das desigualdades sociais e a diminuição da pobreza avançaram de forma sustentada. Houve uma melhora progressiva no mercado de trabalho devido à retomada do crescimento econômico, à política de valorização do salário mínimo e à atuação de algumas instituições públicas. Os autores destacam algumas mudanças importantes verificadas nesse período: redução das taxas médias de desemprego aberto nas regiões metropolitanas e nos municípios; expansão do emprego assalariado formal; crescimento do emprego nos setores mais organizados da economia, incluindo as grandes empresas e o setor público; redução dos postos de trabalho sem carteira e do trabalho por conta própria; elevação do valor real do rendimento médio; diminuição do trabalho não remunerado e expressiva redução do trabalho infantil.

Ainda segundo os autores, ao longo dos anos 2000 houve um esforço a fim de consolidar uma matriz institucional para a promoção de direitos para mulheres e o combate à discriminação por raça. Assim, o Ministério do Trabalho e do Emprego instituiu a Comissão de Igualdade de Oportunidades de Gênero, Raça e Etnia, de Pessoas com Deficiência e de Combate à Discriminação, e o Ministério Público do Trabalho instituiu a Coordenadoria Nacional de Promoção de Igualdade de Oportunidades e Eliminação da Discriminação no Trabalho. Os autores também destacam a importância das ações da então existente Secretaria de Políticas de Promoção da Igualdade Racial no Brasil (SEPPIR). Essas mudanças institucionais e a melhoria na situação econômica do país possibilitaram a criação de oportunidades de emprego e renda para milhões de trabalhadores, inclusive para aqueles com baixa qualificação profissional, informam Proni e Gomes (2015).

Deve-se também destacar que naquele período os trabalhadores negros conseguiram obter maior proteção social. Em primeiro lugar, desde os anos 1990 já vinha ocorrendo um aumento progressivo no número de mulheres e negros com renda equivalente a um salário mínimo. Como explica Arretche (2015), a política do salário mínimo é um divisor de águas na renda dos indivíduos menos qualificados: "A incorporação ao universo dos protegidos pela política do salário mínimo reduz a desigualdade entre faixas de renda e elimina a desigualdade

\footnotetext{
4 Paixão faz referência à Pesquisa de Emprego e Desemprego realizada em 1999 pelo Dieese. A referida pesquisa mostra que o percentual de ocupados em postos de trabalho mais vulneráveis, segundo a cor/raça, em 1998, era a seguinte: em São Paulo, 42,2\% eram negros e 32,2\% brancos e amarelos; em Salvador, 46,2\% eram negros e $27,3 \%$ eram brancos e amarelos; em Recife, $44,7 \%$ eram negros e $36,8 \%$ eram brancos e amarelos; no Distrito Federal, a proporção de negros chegou a 35,4\%, e a de brancos e amarelos ficou em 25,2\%; em Belo Horizonte, a proporção de negros atingiu 40,3\%, e a de brancos e amarelos foi de 31,1\%; por fim, em Porto Alegre, o percentual de negros era de $43,3 \%$, e o de brancos e amarelos, de $32,4 \%$.
} 
entre categorias de cor e gênero" (p. 440). Em segundo lugar, deve-se citar a Lei Complementar 128, de 2008, que regularizou a figura do microeemprendedor individual (MEI), possibilitando a formalização de milhares de microempreendimentos ${ }^{5}$. Em terceiro lugar, em 2013 ocorreu a aprovação da PEC das domésticas, que ampliou o acesso a direitos desse grupo populacional. Assim, essas trabalhadoras passaram a ter acesso a benefícios como adicional noturno, obrigatoriedade do recolhimento do FGTS por parte do empregador; seguro desemprego; salário-família; auxílio creche e pré-escola; seguro contra acidentes de trabalho e indenização em caso de acidente sem justa causa. Desse modo, ainda que em ritmo lento, nesse contexto as desigualdades raciais continuaram a diminuir.

Um problema importante para a população negra no mercado de trabalho é o fato de ela ser particularmente tributária da conjuntura. Por um lado, nos períodos de crescimento econômico ela consegue obter melhorias muito lentas em sua forma de inserção e participação nessa esfera social; por outro, nos momentos de crise, os trabalhadores negros são os primeiros a serem dispensados. Por isso, as desigualdades que vinham diminuindo em ritmo bastante lento voltaram a se ampliar a partir de 2015.

Como explicam Proni e Gomes (2015), a recessão econômica desse período afetou diretamente o mercado de trabalho nacional, fazendo aumentar a taxa de desemprego e a porcentagem de ocupações informais. Ao mesmo tempo, o rendimento médio dos trabalhadores diminuiu. A questão sublinhada pelos autores é que a gravidade dessa conjuntura desfavorável afeta de modo mais forte os trabalhadores mais vulneráveis do ponto de vista ocupacional. Assim, a recessão econômica e seus impactos sobre a geração de emprego formal e as oportunidades de renda mudaram a percepção de que as desigualdades raciais vinham se reduzindo gradualmente no mercado de trabalho.

Dados mais recentes são ainda mais preocupantes. De acordo com o IBGE (2018), as pessoas negras - pretas e pardas - representam a maior parte da força de trabalho do país, perfazendo um contingente de 57,7 milhões de pessoas, contra um total de 46,1 milhões de pessoas brancas. No entanto, em relação à população desocupada e subutilizada, que inclui além dos desocupados os subocupados e a força de trabalho em potencial, as pessoas pretas e pardas são mais representadas, formando cerca de dois terços dos desocupados $(64,2 \%)$ e dos subutilizados $(66,1 \%)$ da força de trabalho em 2018 . Vale notar que as taxas de subutilização e desocupação da população negra são maiores que as da população branca, independentemente do nível de ensino, ainda que a diferença para indivíduos com ensino superior seja ligeiramente menor.

Outro dado apresentado pelo IBGE revela que em 2018 o percentual de trabalhadores negros no trabalho informal era de $47,3 \%$, sendo que no Norte e no Nordeste do país esse percentual sobe para $60 \%$. Desse modo, observando-se a realidade brasileira, praticamente de cada dois trabalhadores negros um é informal, e isso significa que ele não tem acesso aos benefícios da proteção social. Deve-se considerar também que a inserção precária tem impacto sobre o rendimento recebido no trabalho.

Assim, tendo por base o ano de 2018, o IBGE informa que o rendimento médio real habitual do trabalho principal das pessoas pretas e pardas ocupadas no trabalho formal era de $\mathrm{R} \$ 2.082,00$, enquanto que no trabalho informal ficava em $\mathrm{R} \$ 1.050,00$, o que corresponde

5 Dados da pesquisa "Os Donos do negócio no Brasil", realizada pelo Serviço Brasileiro de Apoio às Micro e Pequenas Empresas (Sebrae) em 2015 revelam que dos 23,5 milhões de donos de negócio no país, a maior parte (52\%) é composta por negros. Desses 11,8 milhões de pequenos empresários pretos e pardos, $85 \%$ são conta própria e apenas $15 \%$ são empregadores. A pesquisa também revela que cerca de $30 \%$ dos empreendedores autodeclarados pretos e pardos são mulheres. 
a praticamente a metade. Outro dado alarmante se refere ao trabalho doméstico, que é uma ocupação típica de mulheres negras. Em 2017, o número de pessoas que realizavam esse tipo de atividade bateu recorde, sendo que 6,3 milhões de pessoas estavam no trabalho doméstico ${ }^{6}$. Desse total, apenas 1,7 milhão tinha carteira de trabalho assinada. Cumpre assinalar que o percentual de domésticas com carteira assinada vem diminuindo: eram 46,1\% em 2016, caiu para 45,4\% em 2017 e ficou em 43,5\% em 2018. O salário médio de um empregado doméstico sem carteira foi de R $\$ 755,00$ em novembro; já aqueles que tinham carteira assinada receberam $\mathrm{R} \$ 1.269,00^{7}$.

Procurou-se evidenciar nesta etapa não apenas a vulnerabilidade do trabalhador negro, mas também as desiguadades raciais existentes no mercado de trabalho, que revelam a existência de um privilégio branco nessa esfera social. Ainda que a informalidade e a precarização não sejam problemas exclusivos da população negra, é bem verdade que esse grupo, até então, está mais sujeito a esse tipo de problema. Como veremos a seguir, no momento atual, em consequência da reforma trabalhista, há um risco iminente de que grande parte dos trabalhadores passe a se inserir de modo subalterno nessa esfera social.

\section{REFORMA TRABALHISTA E O DEVIR NEGRO DO MUNDO}

Nesta etapa do artigo, argumenta-se que as transformações que vêm ocorrendo no mercado de trabalho brasileiro, sobretudo após a aprovação da reforma trabalhista, em vez de ampliarem as possibilidades de inserção e participação virtuosa nessa esfera social estão provocando uma maior vulnerabilidade para o conjunto de trabalhadores. Nesse contexto, há uma tendência de que problemas como precarização e informalidade, que atingem majoritariamente os trabalhadores negros, passem a assombrar um percentual cada vez maior da população economicamente ativa, independentemente de suas características adscritas ou adquiridas.

A história do capitalismo está diretamente ligada ao nascimento da questão da raça. Mbembe (2014) argumenta que negro e raça, para o imaginário das sociedades europeias, têm significado a mesma coisa. Sendo produto de uma máquina social e técnica indissociável do capitalismo, de sua emergência e globalização, o nome 'negro' foi inventado para significar exclusão, embrutecimento e degradação, isto é, um limite sempre conjurado e abominado (MBEMBE, 2014). Na ordem da modernidade, o negro é o único de todos os humanos cuja carne foi transformada em coisa e o espírito em mercadoria - a cripta viva do capital. Ainda segundo Mbembe, desse modo o motor primeiro do capitalismo está relacionado a um duplo instinto: 1) de violação ilimitada de todas as formas de interdito; 2) de abolição de qualquer distinção entre os meios e os fins. A fim de exercer seu poder predador, seu poder autoritário ou seu poder polarizador, o capitalismo sempre precisou de subsídios raciais para explorar os recursos do planeta (2014).

Para Mbembe, três momentos marcam a biografia do negro. O primeiro tem a ver com o tráfico atlântico (século XV ao XIX), quando homens e mulheres originários da África foram transformados em homens-objeto, homens-mercadoria e homens-moeda. Essas pessoas passaram a pertencer a outros, que as trataram de modo hostil e não estabeleceram com esse grupo relações co-humanas. O segundo momento teve início no final do século XVIII, quando os negros conseguiram articular uma linguagem para si e passaram a reivindicar o estatuto de

\footnotetext{
${ }^{6}$ Desse total, 3,9 milhões eram mulheres negras. Disponível em: https://economia.uol.com.br/reportagensespeciais/trabalho-domestico-diaristas/\#imagem-1. Acesso em: 1. ${ }^{\circ}$ maio 2020.

7 Disponível em: https://economia.estadao.com.br/noticias/geral,numero-de-empregados-domesticos-no-paisbate-recorde, 70003178662 . Acesso em: $1 .^{\circ}$ maio 2020.
} 
sujeitos completos do mundo vivo. Esse período foi marcado por diversas revoltas de escravos, pela independência do Haiti, por lutas pela abolição do tráfico e pela descolonização africana, pela luta por direitos civis nos Estados Unidos e pelo desmantelamento do apartheid nos últimos anos do século XX. O terceiro momento - início do século XXI - está relacionado à globalização dos mercados, à privatização do mundo sob a égide do neoliberalismo e do crescimento da economia financeira, do complexo militar pós-imperial e das tecnologias eletrônicas e digitais.

O terceiro momento descrito por Mbembe (2014) é a fase em que se apresenta a possibilidade de um devir negro no mundo, isto é, de generalização da condição negra. $\mathrm{O}$ neoliberalismo tem um papel crucial nesse processo. Para o autor, algumas características definem essa doutrina: a) o tempo se presta a ser convertido em força reprodutiva da forma-dinheiro; b) todos os acontecimentos e situações do mundo vivo podem deter um valor no mercado; c) há um processo de produção de indiferença, e a vida social passa a ser codificada em normas, categorias e números; d) o mundo passa a ser racionalizado por meio de lógicas empresariais. Sob a tutela do capital financeiro - característico da fase neoliberal - deixam de existir trabalhadores propriamente ditos e passam a haver tão somente nômades do trabalho.

De acordo com Mbembe, "Se, ontem, o drama do sujeito era ser explorado pelo capital, hoje, a tragédia da multidão é não poder já ser explorada de todo, é ser objeto de humilhação numa humanidade supérflua, entregue ao abandono, que já nem é útil ao funcionamento do capitalismo" (2014, p. 14).

Nesse período vai surgindo um novo ser humano, empresário de si mesmo, plástico e chamado a se reconfigurar de modo permanente em função dos artefatos que a época oferece. Se na primeira fase do capitalismo os negros foram homens-objeto, homens-mercadoria e homens-moeda, no neoliberalismo a humanidade se transforma em homem-coisa, homem-máquina, homem-código e homem-fluxo. Este, por sua vez, procura regular sua conduta em função das normas do mercado: "Condenado à aprendizagem para toda a vida, à flexibilidade, ao reino do curto prazo, abraça a sua condição de sujeito solúvel e descartável para responder à injunção que lhe é constantemente feita - tornar-se outro" (MBEMBE, 2014, p. 15).

Enfim, para Mbembe o neoliberalismo representa a época em que o capitalismo e o animismo se fundem, e os riscos sistemáticos a que os escravos negros foram expostos no primeiro capitalismo passam a constituir, se não a norma, pelo menos o quinhão de todas as humanidades subalternas.

\footnotetext{
Mais característica ainda da potencial fusão do capitalismo e do animismo é a possibilidade, muito distinta, de transformação dos seres humanos em coisas animadas, em dados digitais e em códigos. Pela primeira vez na história humana, o nome Negro deixa de remeter unicamente para a condição atribuída aos genes de origem africana durante o primeiro capitalismo (predações de toda a espécie, desapossamento da autodeterminação e, sobretudo, das duas matrizes do possível, que são o futuro e o tempo). A este novo caráter descartável e solúvel, à sua institucionalização enquanto padrão de vida e à sua generalização ao mundo inteiro, chamamos o devir-negro do mundo (MBEMBE, 2014, p. 18).
}

É possível estabelecer uma relação entre as transformações provocadas no mercado de trabalho pela reforma trabalhista - adotada no Brasil em 2017, por meio da Lei n. ${ }^{\circ} 13.467$, que altera a Consolidação das Leis Trabalhistas que havia sido aprovada em 1. ${ }^{\circ}$ de maio de 1943, e da Lei n. ${ }^{\circ} 13.429$, que ampliou a terceirização e o contrato temporário - e a ideia de devir negro do mundo, pois uma condição social que marcava sobretudo a experiência da população negra tende a se generalizar. Dito em outras palavras, a precarização e a informalidade, bem como a 
ausência de proteção social no mercado de trabalho, surgem no horizonte próximo à maior parte dos trabalhadores. No mesmo sentido, Druck, Dutra e Silva (2019) afirmam que com a reforma a precarização se tornará a regra.

Como explica Krein (2018), a ideia de uma reforma começou a ser discutida ainda nos anos 1980, quando o tema central era a reforma sindical. Na ocasião prevaleceu o fortalecimento da regulamentação estatal com a constitucionalização de diversos direitos. A Constituição de 1988 manteve o caráter flexível da legislação trabalhista, porém reafirmou um modelo de relações de trabalho legislado, havendo uma tendência pluralista.

Ainda segundo Krein, nos governos Collor e, posteriormente, de Fernando Henrique Cardoso, quando o neoliberalismo começou a ganhar terreno, surgiram mais uma vez argumentos para flexibilizar as relações de trabalho com o objetivo de enfrentar o problema do desemprego e da informalidade. No governo de Fernando Henrique Cardoso foram introduzidas algumas medidas, tais como formas de contratação atípica (contrato por prazo determinado e contrato parcial, por exemplo), flexibilização da jornada (banco de horas e autorização para trabalho aos domingos), remuneração variável (fim da indexação ao salário mínimo, por exemplo) e a introdução de mecanismos privados de solução de conflitos. Para Krein, ainda não se pode falar em desestruturação formal do arcabouço legal e institucional existente no país.

Nos anos 2000, Krein destaca que, por um lado, introduziram-se medidas de ampliação da proteção social e de direitos, podendo ser citadas como exemplo a valorização do salário mínimo e a regulamentação do trabalho doméstico; por outro, vinte e uma medidas adotadas reforçaram a lógica da flexibilização e redução da proteção social. Nesse último caso pode-se mencionar a reforma da previdência no setor público de 2003, as restrições do seguro desemprego e do abono salarial. Assim, a agenda de flexibilização ficou presente com avanços e recuos.

O autor destaca que no mundo do trabalho real a flexibilização não parou de avançar, e os empregadores fizeram cada vez mais pressão para alterar as regras formais das relações de trabalho. Em 2013, quando os governos do Partido dos Trabalhadores começaram a dar sinais de esgotamento, a economia iniciou um período de crise as teses mais liberalizantes ganharam força e a pauta da flexibilização foi retomada. Posteriormente, já no contexto de mobilizações pelo impeachment de Dilma Rousseff, foi apresentada uma agenda alternativa para a sociedade que se contrapunha aos governos do PT e previa a diminuição da intervenção estatal ${ }^{8}$.

Com o impedimento da presidenta e o início do governo de Michel Temer, a reforma trabalhista ganha prioridade e é rapidamente aceita. Assim, em 2017 é aprovada a Lei n. ${ }^{\circ} 13.467 / 2017$, que alterou 201 pontos da legislação trabalhista, e a Lei n. ${ }^{\circ} 13.429$, que ampliou a terceirização e o contrato temporário. Druck, Dutra e Silva (2019) chamam atenção para o fato de que essa reforma atende integralmente às proposições empresariais que haviam sido formuladas em agendas e documentos das entidades representativas há alguns anos. Ainda segundo as autoras, a sua aprovação foi possibilitada em razão de se viver em uma conjuntura nacional e internacional - favorável a essa ofensiva de desmonte dos direitos sociais e trabalhistas.

Como argumentam Krein e Colombi (2019), a reforma trabalhista é um instrumento de desconstrução de direitos, que reitera o viés autoritário das políticas ultraneoliberais implementadas no país. Ainda segundo esses autores, a reforma se sustenta no seguinte tripé: flexibilização das modalidades de contratação, da jornada de trabalho e da remuneração (liberalização da terceirização, ampliação do contrato temporário e do contrato parcial, contrato

\footnotetext{
${ }^{8}$ Krein (2018) cita o documento elaborado pelo PMDB, "Uma ponte para o Futuro", que foi apresentado pelo partido com o objetivo de Michel Temer obter apoio da elite econômica com um programa ultraliberal.
} 
intermitente, banco de horas, remuneração variável, entre outras mudanças); flexibilização das instituições públicas e da organização sindical (prevalência do negociado sobre o legislado e fragilização da fiscalização, por exemplo); individualização dos riscos (instabilidade da remuneração e da jornada de trabalho, por exemplo).

Para os autores, de um lado a reforma visa legalizar práticas de flexibilização já existentes no mercado de trabalho brasileiro, tal como a terceirização, o incentivo à remuneração variável e a despadronização da jornada de trabalho; de outro, cria uma série de normas que tornam possível ao empregador ajustar a demanda por mão de obra de acordo com a necessidade das empresas e da dinâmica do mercado, haja vista a criação de novas formas de contratação, como o trabalho intermitente. Há também um ataque às organizações sindicais na medida em que se fragilizam suas fontes de financiamento e seu poder de negociação e organização. $O$ elemento central dessa reforma, para Krein e Colombi, é que se retira do Estado a função de proteção social, se reforçam as desigualdades e se provoca uma responsabilização sobre a vida no trabalho e fora dele para a dimensão individual.

Druck, Dutra e Silva (2019) também salientam que a reforma trabalhista - que foi adotada não somente no Brasil, mas igualmente em países europeus, tais como a Espanha e a França, além de outros países latinos - se pautou na desconstrução do sistema de proteção social como ele era conhecido até então. Essas reformas, segundo as autoras, têm importado em flexibilização e crise do direito do trabalho, tal como ele fora concebido ao longo do século XX. Deve-se acrescentar que o elo construído entre trabalho e proteção social ao longo do desenvolvimento do capitalismo está se tornando cada vez mais frágil, fazendo com que essa atividade fique sujeita tão somente aos imperativos do mercado.

No cenário atual do mercado de trabalho brasileiro há dois problemas: tendência de aumento das desigualdades raciais e de precarização para a massa de trabalhadores. Isso se deve tanto ao baixo crescimento econômico e à adoção de políticas ultraneoliberais pelos governos de Michel Temer e Jair Bolsonaro, que assumiram após o chamado Golpe de 2016, no qual houve a destituição da então presidenta Dilma Rousseff, quanto pela implantação da reforma trabalhista, que legitima e amplia situações de vulnerabilidade já existentes no mercado de trabalho.

Por um lado, as desigualdades entre brancos e negros ainda são bastante expressivas. De acordo com dados do IBGE (2018), a taxa de desocupação da população branca era de $34,6 \%$, ou seja, quase a metade daquela da população preta. Já a taxa de subutilização era de $32,7 \%$, havendo, portanto, uma diferença de 33,4 pontos percentuais. Por fim, a informalidade atingia $34,6 \%$ das pessoas brancas, e como já vimos esse percentual sobe para $47,3 \%$ em relação aos pretos e pardos. Por outro, como explicam Krein e Colombi (2019), apesar de a reforma trabalhista ter como objetivo obter a confiança do mercado para o país voltar a crescer e, consequentemente, gerar emprego, seus primeiros impactos demonstram que os resultados estão longe do esperado. Desse modo, a promessa de segurança econômica vem acompanhada de formas de regulação que acabam por gerar insegurança no emprego, na renda e nos direitos trabalhistas (CARDOSO; AZAIS, 2019).

Além do crescimento da economia ser bastante tímido, demonstrando uma lenta recuperação, o panorama do mercado de trabalho também é desfavorável. Houve uma pequena queda na taxa de desemprego ao longo de 2017, mas isso se deve ao aumento do emprego informal, do trabalho por conta própria e da subocupação, de acordo com Krein e Colombi. Como visto, essas atividades são locus de atuação de boa parte da população negra. Isso significa que os trabalhadores, de modo geral, passam a ter como horizonte de possibilidade inserções vulneráveis e precárias. 
A ideia de devir negro pode ser pensada precisamente com base nesse cenário, pois há uma mudança estrutural no mercado de trabalho que torna todos, tanto brancos quanto negros, igualmente vulneráveis. Krein e Colombi (2019) trazem ainda outro dado bastante alarmante: a informalidade está crescendo não somente entre as atividades de serviço, em que já era bastante presente, mas também entre setores historicamente reconhecidos pela maior incidência de trabalho formal e melhor estruturação. Os autores citam como exemplo o setor industrial, que apresentou um aumento de 5,6\% de trabalhadores informais entre o último trimestre de 2012 e o mesmo período de 2018. Informam ainda que a informalidade cresceu mais entre os trabalhadores com nível superior (incompleto e completo).

O devir negro do mundo também pode ser pensado com base em dados sobre a subutilização da força de trabalho. Krein e Colombi (2019) relatam que a subocupação cresceu de 4,8\% para 7,4\% entre 2014 e 2018, tendo como referência o terceiro trimestre de cada ano. Vale notar que os subocupados trabalham em média 19 horas semanais e têm renda média mensal de $\mathrm{R} \$ 734,00$, enquanto a jornada média dos ocupados é de 38 horas semanais, ficando seu rendimento médio em $\mathrm{R} \$ 2.187,00$. Assim, os autores sublinham que os subocupados trabalham em média metade das horas e recebem um terço dos rendimentos dos ocupados. Como já mencionado anteriormente, a subocupação já é particularmente elevada entre os trabalhadores negros, revelando uma tendência de nivelamento entre todos os trabalhadores. Outro problema é que o aumento da informalidade e o incremento de atividades com remuneração mais baixa provocam não apenas a desestruturação do mercado de trabalho, mas também a destruição das fontes de financiamento da seguridade social, tornando o déficit da previdência uma profecia autorrealizável, segundo Krein e Colombi.

Outro fator que tem relação direta com o devir negro do mundo é a ampliação da possibilidade de terceirização. Até esse momento, as pessoas negras são as que mais sofrem com a terceirização, pois serviços de limpeza e de vigilância - tanto no âmbito público quanto no privado - foram os primeiros a adotar essa modalidade de contratação e empregam majoritariamente indivíduos negros. Como destacam Druck, Dutra e Silva (2019), o impacto das modificações legislativas é pequeno para os trabalhadores que já eram terceirizados, tendo em vista que eles já não alcançavam o conteúdo de muitos dos direitos que foram extintos ou flexibilizados; por outro lado, há uma tendência de os trabalhadores que não experimentavam a condição de trabalho terceirizado vivenciarem a mesma intensidade da precarização incidente aos casos de terceirização.

Krein e Colombi destacam que após a reforma a geração de ocupações ficou concentrada em atividades mais precárias e houve crescimento da informalidade, da subocupação e das atividades tipicamente terceirizáveis. A análise de Cardoso e Azais (2019) vai no mesmo sentido. Esses autores, tomando por base três indicadores - desemprego, informalidade e condição "nem nem" - afirmam que não houve melhoria nas condições de inserção das pessoas no mercado de trabalho após a implantação da reforma.

O desemprego continuou alto, a informalidade aumentou com a retomada do crescimento, as chances de um desempregado estar ocupado não tiveram variação significativa mesmo em meio ao (leve) crescimento econômico iniciado em 2017, e as chances de um trabalhador informal em um ano estar em melhor posição no ano seguinte tampouco variaram substancialmente, permanecendo muito baixas, tanto para homens quanto para mulheres. A reforma, na verdade, está associada com o aumento da precariedade no mercado de trabalho brasileiro (CARDOSO; AZAIS, 2019, p. 315-316).

\footnotetext{
9 Pessoas em idade ativa que "nem estudam nem trabalham".
} 
Cabe mencionar ainda que aqueles que viraram trabalhadores 'conta própria' depois da crise encararam trabalhos menos protegidos, em postos menos qualificados e com remuneração $33 \%$ inferior àquela recebida por aqueles que estavam há mais tempo nessa posição na ocupação, de acordo com o Dieese (2018). Segundo o mesmo órgão, considerando os trabalhadores por conta própria há menos de dois anos, $77 \%$ não tinham CNPJ nem contribuíam para a Previdência Social. Outro fator destacado pelo estudo é que a maioria (52\%) dos trabalhadores por conta própria em ocupações elementares (tais como faxineiros, pedreiros, preparadores de comida rápida etc.) entrou nesse trabalho há menos de dois anos. Esse dado indica não só a ausência de proteção social, mas igualmente a queda na qualidade do trabalho.

Pode-se concluir que há um quadro de desproteção social, e que em vez da ampliação da justiça no mercado de trabalho, abarcando um percentual paulatinamente maior de indivíduos para formas de assalariamento estáveis e protegidas, apresenta-se um panorama reverso, que remete a formas cada vez mais precárias e vulneráveis de trabalho. E o trabalhador negro, que aspirava ter condições igualitárias a uma boa parcela dos indivíduos brancos, agora vislumbra em seu horizonte a generalização de sua condição subalterna.

\section{CONCLUSÃO}

Este artigo buscou analisar a relação entre a reforma trabalhista e o processo de desproteção social. Procurou-se demonstrar que com o desenvolvimento do capitalismo e da industrialização surgiu uma questão social que tornou possível a emergência de meios de regulação do conflito capital-trabalho. Assim, apareceram aos poucos formas de proteção social que passaram a salvaguardar os trabalhadores de uma série de riscos, tais como velhice, invalidez, desemprego etc. Também é importante sublinhar que a inserção no mercado de trabalho formal foi se atrelando à cidadania devido aos direitos que passaram a ser acessados. No entanto, a partir de meados dos anos 1970, começou a ocorrer um processo de inversão histórica. Diante da crise estrutural do capital, houve um avanço do neoliberalismo e das medidas que defendem o mínimo de intervenção do Estado no social. Nesse contexto, ocorreu um ataque às medidas de proteção social e às tentativas de mediar o conflito entre capital e trabalho.

No Brasil, a reforma trabalhista implantada a partir de 2017 é uma medida exemplar de desproteção social, pois provoca um processo de desmonte de direitos (KREIN, 2018; DRUCK; DUTRA; SILVA, 2019; CARDOSO; AZAIS; 2019). Os elementos centrais do emprego - tais como formas de contratação, jornada, remuneração e proteção social - foram transformados sob a égide dessa reforma, provocando ao menos duas consequências importantes: a) os trabalhadores tornam-se cada vez menos protegidos, já que existe uma fragilização e mesmo eliminação de alguns direitos; b) os riscos provocados por essa situação passam a ser vivenciados de forma individual (KREIN, 2018). Ao mesmo tempo em que o trabalhador é responsável por garantir sua empregabilidade em um mercado de trabalho que não apresenta condições nada favoráveis a ele, também precisa arcar sozinho com os riscos do desemprego e da subocupação. Há, portanto, um aumento da vulnerabilidade e da precarização, que tende a igualar a condição de boa parte da população economicamente ativa àquela vivenciada historicamente pela população negra.

Desse modo, o horizonte normativo que havia sido criado pela luta dos trabalhadores se esmaece. Diante desse quadro, recupera-se a ideia de Mbembe (2014) de que há uma relação entre a fase atual do capitalismo - financeiro, globalizado e neoliberal - e o devir negro do mundo. A condição social que havia sido reservada a esse grupo populacional tende a se generalizar. Como se procurou sublinhar, se os negros numa primeira fase do capitalismo foram homens-objeto, homens-mercadoria e homens-moeda, no neoliberalismo a humanidade 
se transformou em homem-coisa, homem-máquina, homem-código e homem-fluxo. Desse modo, a lógica do mercado volta a passar à frente, e o elo entre trabalho e proteção social se torna cada vez mais frágil.

\section{REFERÊNCIAS}

ARENDT, Hannah. A condição humana. Rio de Janeiro: Forense Universitária, 1997.

ARRETCHE, Marta. As políticas na trajetória da democracia à redução das desigualdades. In: ARRETCHE, Marta. (Org.). Trajetória das desigualdades: como o Brasil mudou nos últimos cinquenta anos. São Paulo: Ed. Unesp; CEM, 2015.

ARRETCHE, Marta. Emergência e Desenvolvimento do Welfare State: teorias explicativas. Revista Brasileira de Informação Bibliográfica em Ciências Sociais, n. 39, p. 3-40, 1995.

CARDOSO, Adalberto; AZAÏS, Christian. Reformas trabalhistas e seus mercados: uma comparação Brasil-França. Caderno CRH, v. 32, n. 86, p. 307-323, maio/ago. 2019.

CARDOSO, Fernando Henrique. Capitalismo e escravidão no Brasil meridional: o negro na sociedade escravocrata do Rio Grande do Sul. Rio de Janeiro: Civilização Brasileira, 2003.

CARVALHO, José Murilo. Cidadania no Brasil: o longo caminho. Rio de Janeiro: Civilização Brasileira, 2008.

CASTEL, Robert. As metamorfoses da questão social: uma crônica do salário. Petrópolis: Vozes, 1998.

CASTELLS, Manuel. A sociedade em rede. A era da informação: economia, sociedade e cultura. São Paulo: Paz e Terra, 1999. v. 1.

COMIN, Álvaro A. Desenvolvimento econômico e desigualdades no Brasil: 1960-2010. In: ARRETCHE, Marta. (Org.). Trajetória das desigualdades: como o Brasil mudou nos últimos cinquenta anos. São Paulo: Ed. da Unesp; CEM, 2015.

DARDOT, Pierre; LAVAL, Christian. A nova razão do mundo: ensaio sobre a sociedade neoliberal. São Paulo: Boitempo, 2016.

DIEESE. Trabalho por conta própria cresce na crise, mas em piores condições. Boletim emprego em pauta, n. 8, jul. 2018. Disponível em: https://www.dieese.org.br/ boletimempregoempauta/2018/boletimEmpregoEmPauta8.html. Acesso em: 6 jul. 2020.

DRAIBE, Sônia M. O "Welfare State" no Brasil: características e perspectivas. Ciências Sociais Hoje, p. 13-60, 1989.

DRUCK, Graça; DUTRA, Renata; SILVA, Selma C. A contrarreforma neoliberal e a terceirização: a precarização como regra. Caderno CRH, v. 32, n. 86, p. 289-305, maio/ago. 2019.

ESPING-ANDERSEN, Gosta. As três economias políticas do Welfare State. Lua Nova, n. 24, p. 85-116, 1991.

FERNANDES, Florestan. A integração do negro na sociedade de classes. São Paulo: Ática, 1978. v. 1.

FLEURY, Sônia. Estado sem cidadãos: seguridade social na América Latina. Rio de Janeiro: Fiocruz, 1994.

HARVEY, David. Condição pós-moderna: uma pesquisa sobre as origens da mudança cultural. São Paulo: Loyola, 1999. 
HENRIQUES, Ricardo. Desigualdade racial no Brasil: evolução das condições de vida na década de 90. Brasília: IPEA, 2001.

HOBSBAWM, Eric J. Era dos extremos: o breve século XX (1914-1991). São Paulo: Companhia das Letras, 2000.

HONNETH, Axel. El derecho de la libertad: esbozo de uma eticidad democrática. Madrid: Katz, 2014.

IBGE, 2018. Desigualdades sociais por cor ou raça no Brasil. Disponível em: https:// biblioteca.ibge.gov.br/visualizacao/livros/liv101681_informativo.pdf. Acesso em: $1 .^{\text {o }}$ maio 2019.

KREIN, José D. O desmonte dos direitos, as novas configurações do trabalho e o esvaziamento da ação coletiva. Consequências da Reforma Trabalhista. Tempo Social, v. 30, n. 1, p. 77-104, 2018.

KREIN, José D.; COLOMBI, Ana Paula F. A reforma trabalhista em foco: desconstrução da proteção social em tempos de neoliberalismo autoritário. Educação \& Sociedade, v. 40, p. 1-18, 2019.

LOVELL, Peggy. Raça e gênero no Brasil. Lua Nova, n. 35, p. 39-71, 1995.

MARQUES, Rosa M. A proteção social e o mundo do trabalho. São Paulo: Bienal, 1997.

MARX, Karl. O capital: crítica da economia política. São Paulo: Boitempo, 2017.

MBEMBE, Achille. Crítica da razão negra. Lisboa: Antígona, 2014.

ORTIZ, Renato. Cultura brasileira e identidade nacional. São Paulo: Brasiliense, 1985.

PAIXÃO, Marcelo. Desenvolvimento humano e relações raciais. Rio de Janeiro: DP\&A, 2003.

PESAVENTO, Sandra Jatahy. A emergência dos subalternos: trabalho livre e ordem burguesa. Porto Alegre: Ed. da UFRGS: Fapergs, 1989.

POCHMANN, Márcio. O trabalho sob fogo cruzado: exclusão, desemprego e precarização no final do século. São Paulo: Contexto, 1999.

POCHMANN, Márcio. Rumos da política do trabalho no Brasil. In: SILVA. Maria O.; YAZBEK, Maria C. Políticas públicas de trabalho e renda no Brasil Contemporâneo. São Paulo: Cortez; São Luís: Fapema, 2008.

PRONI, Marcelo W.; GOMES, Darcilene C. Precariedade ocupacional: uma questão de gênero e raça. Estudos Avançados, v. 29, n. 85, p. 137-152, 2015.

QUIJANO, Anibal. Colonialidade do poder, eurocentrismo e América Latina. In: A Colonialidade do saber: eurocentrismo e ciências sociais. Perspectivas Latino-Americanas. Buenos Aires: Clacso, 2005. Disponível em: http://bibliotecavirtual.clacso.org.ar/clacso/sursur/20100624103322/12_Quijano.pdf. Acesso em: 26 jul. 2018.

SANTOS, Boaventura de S. Pela mão de Alice: o social e o político na pós-modernidade. São Paulo: Cortez, 1996.

SEBRAE, 2015. Os donos do negócio no Brasil: análise por raça/cor. Disponível em: https://m. sebrae.com.br/Sebrae/Portal\%20Sebrae/Anexos/DN_Ra\%C3\%A7a_Cor.pdf. Acesso em: 1. ${ }^{\circ}$ maio 2019. 
SILVA, Nelson; HASENBALG, Carlos A. Relações raciais no Brasil contemporâneo. Rio de Janeiro: Rio Fundo, Ed. IUPERJ, 1992.

SKIDMORE, Thomas E. Preto no branco: raça e nacionalidade no pensamento brasileiro. Rio de Janeiro: Paz e Terra, 1989.

TEIXEIRA, Sônia M. Política social e democracia: reflexões sobre o legado da seguridade social. Cadernos de Saúde Pública, v. 1, n. 4, p. 400-417, 1985.

TELLES, Edward. Racismo à brasileira: uma nova perspectiva sociológica. Rio de Janeiro: Relume Dumará, Fundação Ford, 2003. 